\title{
The Intrinsic Nature of Persulfate Activation and N-doping in Carbocatalysis
}

Wei Ren ${ }^{a, b}$, Gang Nie ${ }^{a, b}$, Peng Zhou ${ }^{b, c}$, Hui Zhang ${ }^{a^{*}}$, Xiaoguang Duan ${ }^{\text {b** }}$, Shaobin Wang ${ }^{b}$

${ }^{a}$ Department of Environmental Science and Engineering, Wuhan University, Wuhan 430079, China.

b School of Chemical Engineering and Advanced Materials, The University of Adelaide, Adelaide, SA5005, Australia

${ }^{\mathrm{c}}$ College of Architecture \& Environment, Sichuan University, Chengdu 610065, China

*Corresponding author. E-mail: eeng@whu.edu.cn (H. Zhang).

** Corresponding author. E-mail: xiaoguang.duan@adelaide.edu.au (X. Duan).

This Supporting Information includes

\section{Pages}

1 Table

2 Texts

17 Figures 


\section{List of text, table and figures}

Text S1. Electrochemical analysis tests.

Text S2. Evaluation of carbocatalyst activity.

Table S1. The physicochemical properties of three commercial CNTs.

Figure S1. The degradation curves of phenol by the PMS/CNT and the PMS/N-CNT systems with CNT-A and N-CNT-A materials (a), CNT-B and N-CNT-B materials (b), CNT-C and N-CNT-C materials (c), and their pseudo-first order kinetic constant $\ln k_{\mathrm{obs}}(\mathrm{d}) .\left([\mathrm{PMS}]_{0}=0.2 \mathrm{mM},[\mathrm{CNT}]_{0}=0.1\right.$ $\mathrm{g} / \mathrm{L},[\mathrm{PE}]_{0}=0.1 \mathrm{mM}, \mathrm{T}=25^{\circ} \mathrm{C}$ and $\left.\mathrm{pH}_{0} 4.0\right)$

Figure S2. The surface N1s XPS spectra of CNT-A and N-CNT-A materials (a), CNT-B and N-CNTB materials (b), and CNT-C and N-CNT-C materials (c).

Figure S3. The adsorption curves of PMS by CNT-A and N-CNT-A materials (a), CNT-B and N-CNTB materials (b), CNT-C and N-CNT-C materials (c), and correlation between $\ln k_{\text {obs }}$ and PMS adsorption quantity (d). ([PMS $]_{0}=0.2 \mathrm{mM},[\mathrm{CNT}]_{0}=0.1 \mathrm{~g} / \mathrm{L}, \mathrm{T}=25^{\circ} \mathrm{C}$ and $\left.\mathrm{pH}_{0} 4.0\right)$

Figure S4. Open-circuit potential curves with the addition of $0.2 \mathrm{mM}$ PMS on different CNT-A and N-CNT-A electrodes (a), CNT-B and N-CNT-B electrodes (b), and CNT-C and N-CNT-C electrodes (c), and the potential of the complexes of CNT/PMS and N-CNT/PMS systems (d). ([PMS $]_{0}=0.2 \mathrm{mM}$, $[\mathrm{CNT}]_{0}=0.1 \mathrm{~g} / \mathrm{L}, \mathrm{T}=25^{\circ} \mathrm{C}$ and $\left.\mathrm{pH}_{0} 4.0\right)$

Figure S5. In situ Raman spectra of the PDS/CNT-B and PDS/N-CNT-B1 systems.

Figure S6. Raman spectra of CNT-A and N-CNT-A materials (a), CNT-B and N-CNT-B materials (b), CNT-C and N-CNT-C materials (c), and the correlation of $\ln k_{\mathrm{obs}}$ to $\mathrm{I}_{\mathrm{D}} / \mathrm{I}_{\mathrm{G}}$ of CNT and N-CNT materials (d).

Figure S7. The effects of initial PMS concentration on the degradation of phenol in the PMS/CNT-B (a) and the PMS/N-CNT-B1 (b) systems, on the PMS consumption without or with phenol in the PMS/CNT-B (c) and PMS/N-CNT-B1 (d) systems, and the open-circuit potential of the CNT-B (e) and the N-CNT-B1 (f) electrodes. $\left([\mathrm{CNT}]_{0}=0.1 \mathrm{~g} / \mathrm{L},[\mathrm{PE}]_{0}=0.1 \mathrm{mM}, \mathrm{T}=25^{\circ} \mathrm{C}\right.$ and $\left.\mathrm{pH}_{0} 4.0\right)$

Figure S8. The effects of initial PDS concentration on the degradation of phenol in the PDS/CNT-B (a) and the PDS/N-CNT-B1 (b) systems, on PDS adsorption without phenol in the PDS/CNT-B (c) and 
the PDS/N-CNT-B1 (d) systems, and on the open-circuit potential of the CNT-B (e) and the N-CNTB1 (f) electrodes. $\left([\mathrm{CNT}]_{0}=0.1 \mathrm{~g} / \mathrm{L},[\mathrm{PE}]_{0}=0.1 \mathrm{mM}, \mathrm{T}=25^{\circ} \mathrm{C}\right.$ and $\left.\mathrm{pH}_{0} 4.0\right)$

Figure S9. The comparison of $k_{\mathrm{obs}}$ between the persulfate/CNT-B and the persulfate/N-CNT-B1 systems with different initial PMS (a) and PDS (b) concentrations.

Figure S10. The comparison of N1s XPS spectra of N-CNT-B1 after persulfate activation.

Figure S11. PMS adsorption (a) and PDS adsorption (b) in the persulfate/N-CNT-B1 systems at different initial pHs. $\left([\text { persulfate }]_{0}=0.2 \mathrm{mM},[\mathrm{N}-\mathrm{CNT}-\mathrm{B} 1]_{0}=0.1 \mathrm{~g} / \mathrm{L}\right.$ and $\mathrm{T}=25^{\circ} \mathrm{C}$ )

Figure S12. Zeta potentials of CNT-B and N-CNT-B1 in different pHs (a); and correlation of persulfate adsorption quantity with the Zeta potential of N-CNT-B1 (b).

Figure S13. Zeta potentials of different CNT materials (a) and correlation of PMS adsorption quantity with the Zeta potential (b). ( $\mathrm{T}=25^{\circ} \mathrm{C}$ and $\left.\mathrm{pH}_{0} 4.0\right)$

Figure S14. The effect of inorganic ions on PMS adsorption (a) and PE degradation (b) in the PMS/NCNT-B1 system. $\left([\mathrm{PMS}]_{0}=0.2 \mathrm{mM},[\mathrm{N}-\mathrm{CNT}-\mathrm{B} 1]_{0}=0.1 \mathrm{~g} / \mathrm{L},[\mathrm{PE}]_{0}=0 \text { or } 0.1 \mathrm{mM} \text {, [inorganic ions }\right]_{0}$ $=10 \mathrm{mM}, \mathrm{T}=25{ }^{\circ} \mathrm{C}$ and $\left.\mathrm{pH}_{0} 4.0\right)$

Figure S15. The degradation curves of phenol with equal adsorption quantity of persulfate on the CNTB and N-CNT-B1 materials (a), the corresponding pseudo-first-order kinetics (b), and the change of persulfate adsorption (c) by persulfate/CNT and persulfate/N-CNT systems. $\left([\mathrm{CNT}]_{0}=0.1 \mathrm{~g} / \mathrm{L},[\mathrm{PE}]_{0}\right.$ $=0.1 \mathrm{mM}, \mathrm{T}=25^{\circ} \mathrm{C}$ and $\mathrm{pH}_{0} 4.0$ )

Figure S16. The degradation curves of phenol with equal potential of complexes on the CNT-B and N-CNT-B1 materials (a), the corresponding pseudo-first-order kinetics (b), and the change of persulfate adsorption (c) by persulfate/CNT and persulfate/N-CNT systems. $\left([\mathrm{CNT}]_{0}=0.1 \mathrm{~g} / \mathrm{L},[\mathrm{PE}]_{0}\right.$ $=0.1 \mathrm{mM}, \mathrm{T}=25^{\circ} \mathrm{C}$ and $\left.\mathrm{pH}_{0} 4.0\right)$

Figure S17. The electrochemical impedance spectroscopy profiles of the CNT-B and N-CNT-B1 electrodes in the electrolyte solution. $\left(\left[\mathrm{Na}_{2} \mathrm{SO}_{4}\right]_{0}=50 \mathrm{mM}, \mathrm{T}=25^{\circ} \mathrm{C}\right.$ and $\left.\mathrm{pH}_{0} 4.0\right)$ 
Text S1. Electrochemical analysis tests.

\section{(1) Preparation of CNT-coated glassy carbon electrode (CNT-GCE)}

A CNT-GCE was prepared by dipping GCE in a mixed isopropanol solution with CNT and Nafion perfluorinated resin (the binder). After drying, the CNT-GCE was immersed in an aqueous solution overnight to maintain a stable potential.

\section{(2) Analysis of linear sweep voltammetry (LSV)}

LSV was performed between $0.5 \mathrm{~V}$ and $1.0 \mathrm{~V}$ at a scan rate of $20 \mathrm{mV} \mathrm{s}^{-1}$ using an electrochemical workstation. The experiments were conducted in $50 \mathrm{mM} \mathrm{Na}_{2} \mathrm{SO}_{4}$ solution, $0.1 \mathrm{mM}$ phenol and $\mathrm{pH}_{0}$ at 4.0 with a three-electrodes-cell configuration, including a working electrode ( $\Phi 3 \mathrm{~mm}$ glassy carbon electrode), a counter electrode (platinum electrode), and a reference electrode ( $\mathrm{Ag} / \mathrm{AgCl}$ electrode).

\section{(3) Analysis of Tafel curve}

The operational process of Tafel curve was the same as LSV except the current transforming into an exponential form. 
Text S2. Evaluation of carbocatalyst activity.

The catalytic activities of the materials were evaluated for phenol oxidation with persulfate/carbon, adsorption of persulfate and the potential of carbon-activated persulfate complexes.

\section{(1) Oxidation Kinetics of Phenol}

Kinetic experiments of phenol elimination were conducted in a $100 \mathrm{~mL}$ beaker at a magnetic stirring rate of $600 \mathrm{rpm}$. The reaction was carried out in $60 \mathrm{~mL}$ solution containing $0.1 \mathrm{mM} \mathrm{PE}, 0.1$ $\mathrm{g} / \mathrm{L} \mathrm{N}-\mathrm{CNT}$ and $0.2 \mathrm{mM}$ PMS at $\mathrm{pH} 4.0$ and $25^{\circ} \mathrm{C}$. The liquid samples were periodically collected and quickly filtered through $0.22 \mu \mathrm{m}$ PES (polyether sulfone) filters, and phenol was detected by high performance liquid chromatography (HPLC, DIONEX UltiMate 3000) with a C-18 column. A graph of $\ln \left([\mathrm{PE}]_{t} /[\mathrm{PE}]_{0}\right)$ versus time $t$ would give a straight line with a slope as $k_{\mathrm{obs}}$ (eq. S1), which was used to obtain the value of $\ln k_{\text {obs. }}$. The kinetic fitting started from the second point to minimize the influence of adsorption of PE on carbonaceous materials.

$$
\ln \left([\mathrm{PE}]_{\mathrm{t}} /[\mathrm{PE}]_{0}\right)=-k_{o b s} \times t
$$

where $[\mathrm{PE}]_{0}$ and $[\mathrm{PE}]_{\mathrm{t}}$ are the respective concentrations of $\mathrm{PE}$ at initial and reaction stages $(\mathrm{t})$.

\section{(2) Adsorption of Persulfate}

For the measurement of the adsorption quantity of persulfate, $0.1 \mathrm{~g} / \mathrm{L} \mathrm{N}-\mathrm{CNT}$ was added into 60 $\mathrm{mL}$ persulfate (PDS or PMS) solution $(0.2 \mathrm{mM})$ and solution $\mathrm{pH}$ was adjusted to 4.0. After mixing in a $100 \mathrm{~mL}$ beaker for $20 \mathrm{~min}$ by a magnetic stir at $600 \mathrm{rpm}$ and $25^{\circ} \mathrm{C}$, the residual persulfate (PDS or PMS) was determined by a potassium iodide method. ${ }^{\mathrm{S} 1}$ The persulfate adsorption quantity was calculated by eq. S2.

$$
Q=\frac{[\text { persulfate }]_{0}-[\text { persulfate }]_{\mathrm{t}}}{m}
$$


where $Q$ represents the persulfate adsorption quantity; [persulfate] 0 and [persulfate] $]_{\mathrm{t}}$ are the concentrations of persulfate at initial and final stages, respectively; $m$ is the mass of carbonaceous materials.

\section{(3) Measurement of open circuit potential}

The open circuit potential of CNT-GCE was monitored by chronopotentiometry analysis using an $\mathrm{Ag} / \mathrm{AgCl}$ electrode as the reference electrode. Firstly, the $\mathrm{pH}$ of high-concentrated PMS solution (100 $\mathrm{mM}$ ) and solvent (ultrapure water) was both adjusted to 4.0. The changing potential of CNT-GCE was

monitored after the open circuit potential of the CNT-GCE was stable in the solution. The potential of the complexes represents the stable equilibrium potential of CNT after adding PMS. 
Table S1. The physicochemical properties of three commercial CNTs. *

\begin{tabular}{cccc}
\hline Test & CNT-A-crude & CNT-B-crude & CNT-C-crude \\
\hline -OH content & - & $3.7 \%$ & - \\
-COOH content & - & - & $2.6 \%$ \\
Electric conductivity & $>10^{5} \mu \mathrm{S} / \mathrm{cm}$ & $>10^{5} \mu \mathrm{S} / \mathrm{cm}$ & $>10^{5} \mu \mathrm{S} / \mathrm{cm}$ \\
Inner Diameter & $3-5 \mathrm{~nm}$ & $3-5 \mathrm{~nm}$ & $3-5 \mathrm{~nm}$ \\
Length & $\sim 50 \mu \mathrm{m}$ & $\sim 50 \mu \mathrm{m}$ & $\sim 50 \mu \mathrm{m}$ \\
Outer Diameter & $8-15 \mathrm{~nm}$ & $8-15 \mathrm{~nm}$ & $8-15 \mathrm{~nm}$ \\
\hline *Note: These data were provided by Sigma-Aldrich Chemical Co. Ltd.
\end{tabular}

*Note: These data were provided by Sigma-Aldrich Chemical Co. Ltd. 

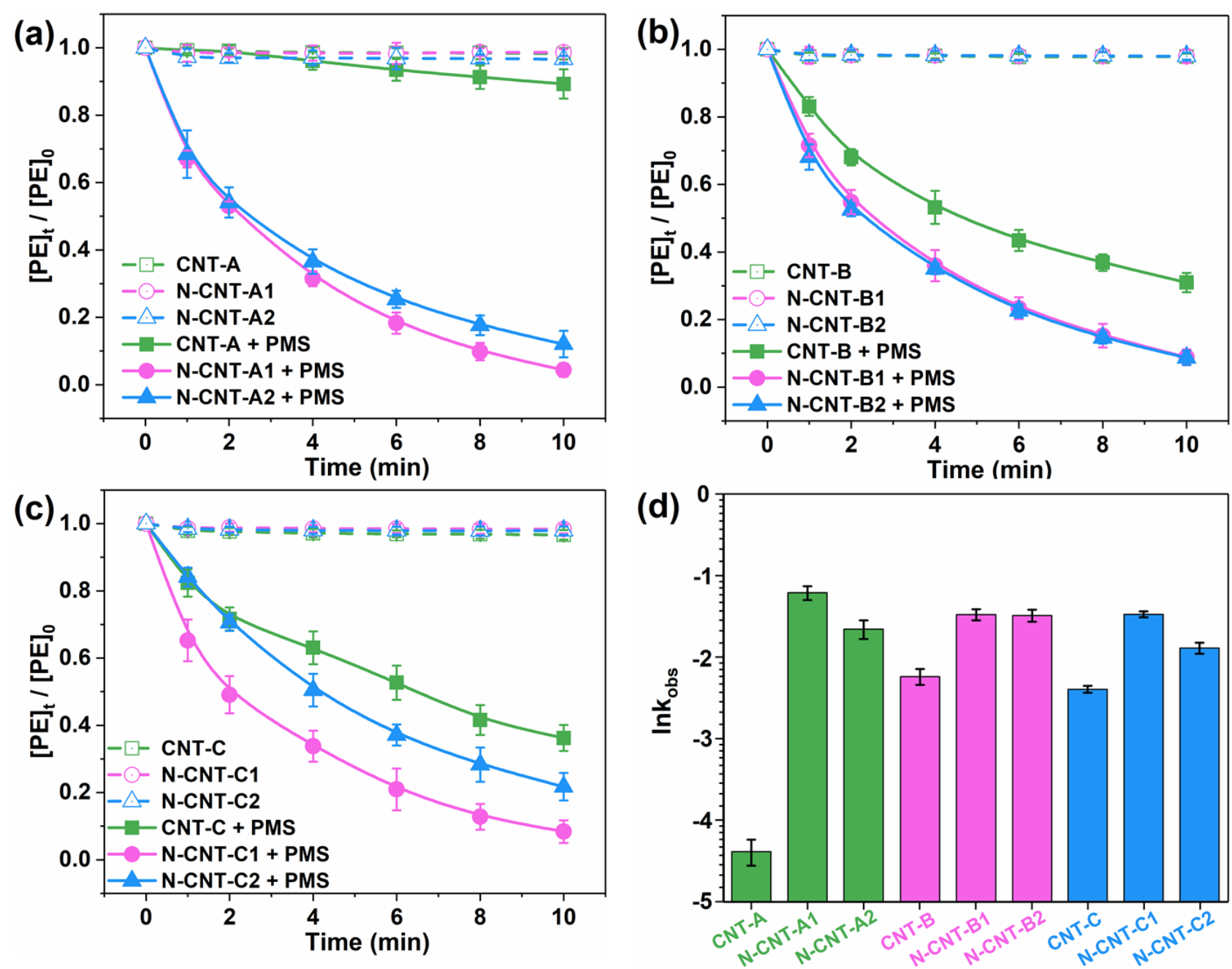

Figure S1. The degradation curves of phenol by the PMS/CNT and the PMS/N-CNT systems with CNT-A and N-CNT-A materials (a), CNT-B and N-CNT-B materials (b), CNT-C and N-CNT-C materials (c), and their pseudo-first order kinetic constant $\ln k_{\mathrm{obs}}(\mathrm{d}) .\left([\mathrm{PMS}]_{0}=0.2 \mathrm{mM},[\mathrm{CNT}]_{0}=0.1\right.$ $\mathrm{g} / \mathrm{L},[\mathrm{PE}]_{0}=0.1 \mathrm{mM}, \mathrm{T}=25^{\circ} \mathrm{C}$ and $\left.\mathrm{pH}_{0} 4.0\right)$ 

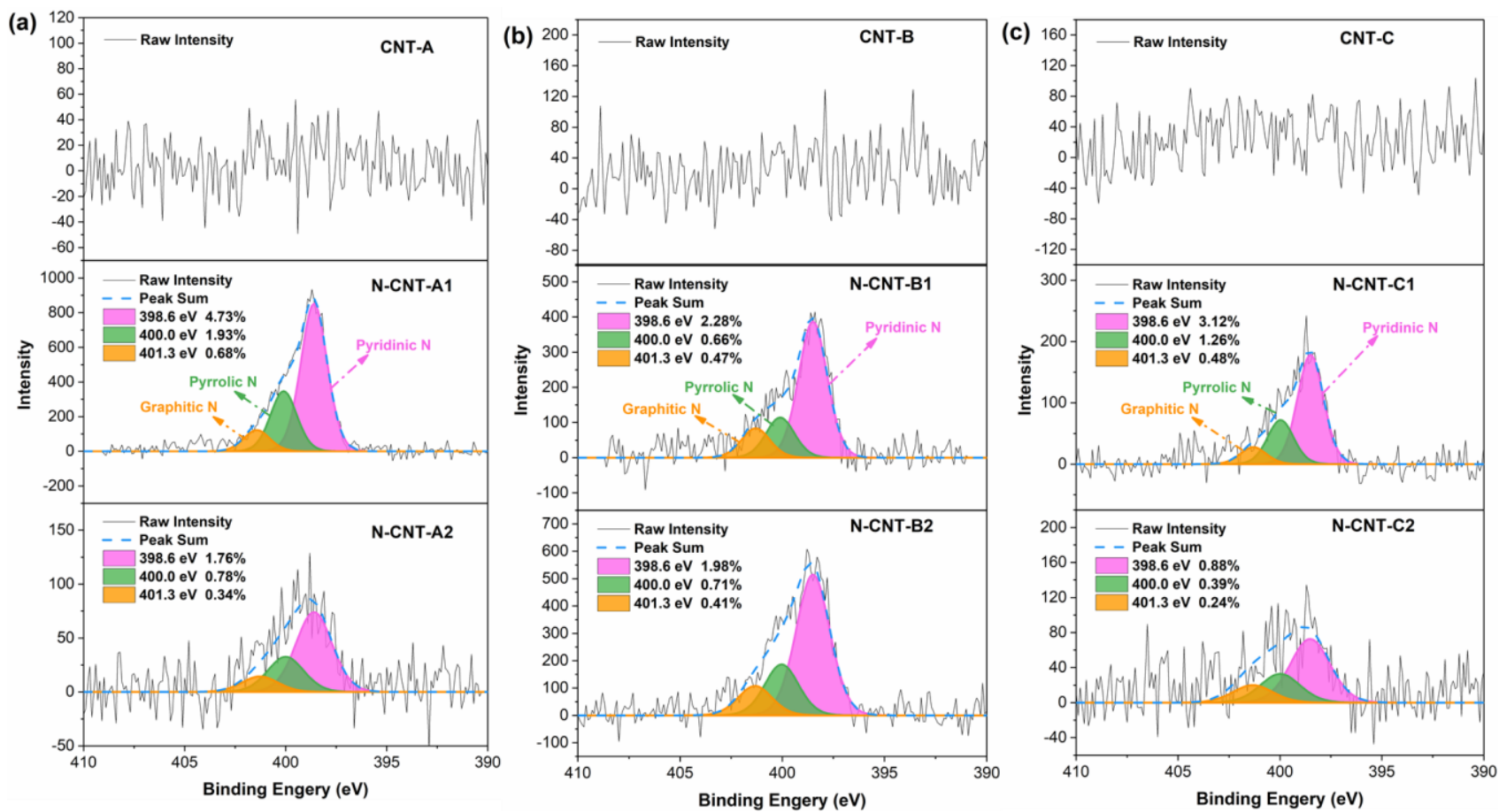

Figure S2. The surface N1s XPS spectra of CNT-A and N-CNT-A materials (a), CNT-B and N-CNTB materials (b), and CNT-C and N-CNT-C materials (c). 

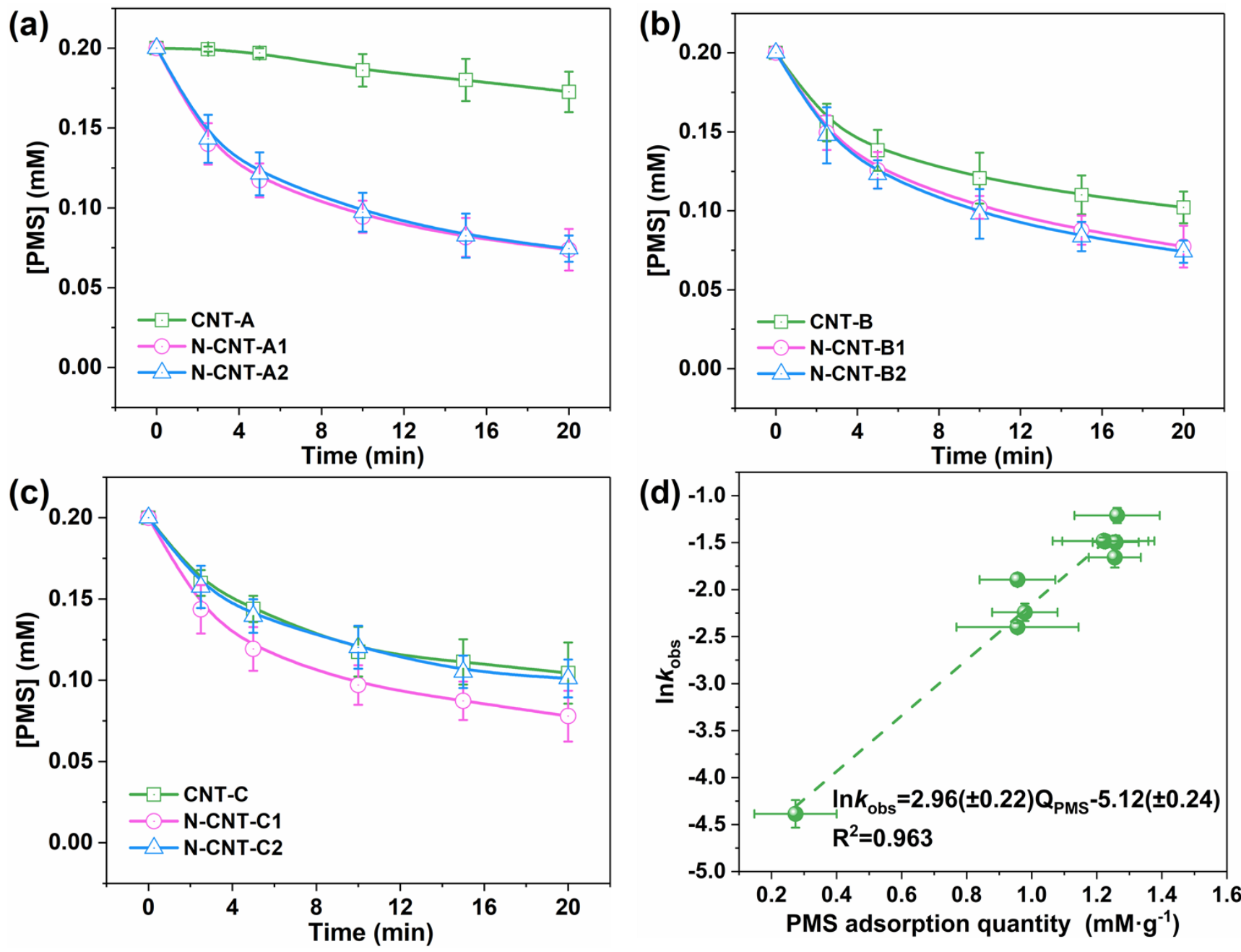

Figure S3. The adsorption curves of PMS by CNT-A and N-CNT-A materials (a), CNT-B and N-CNTB materials (b), CNT-C and N-CNT-C materials (c), and correlation between $\ln k_{\mathrm{obs}}$ and PMS adsorption quantity (d). ([PMS $]_{0}=0.2 \mathrm{mM},[\mathrm{CNT}]_{0}=0.1 \mathrm{~g} / \mathrm{L}, \mathrm{T}=25^{\circ} \mathrm{C}$ and $\left.\mathrm{pH}_{0} 4.0\right)$ 

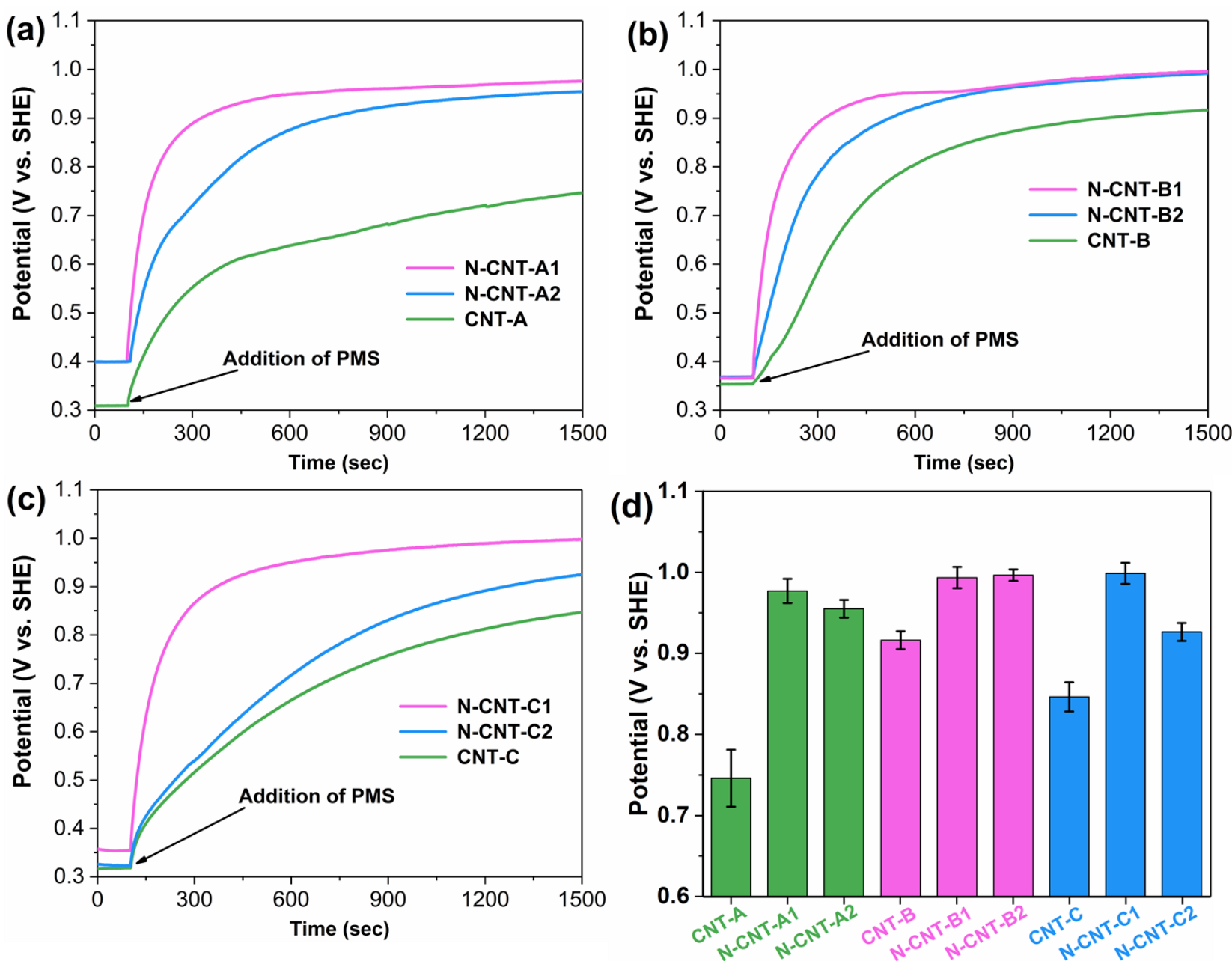

Figure S4. Open-circuit potential curves with the addition of $0.2 \mathrm{mM}$ PMS on different CNT-A and N-CNT-A electrodes (a), CNT-B and N-CNT-B electrodes (b), and CNT-C and N-CNT-C electrodes (c), and the potential of the complexes of CNT/PMS and N-CNT/PMS systems (d). ([PMS $]_{0}=0.2 \mathrm{mM}$, $[\mathrm{CNT}]_{0}=0.1 \mathrm{~g} / \mathrm{L}, \mathrm{T}=25^{\circ} \mathrm{C}$ and $\left.\mathrm{pH}_{0} 4.0\right)$ 


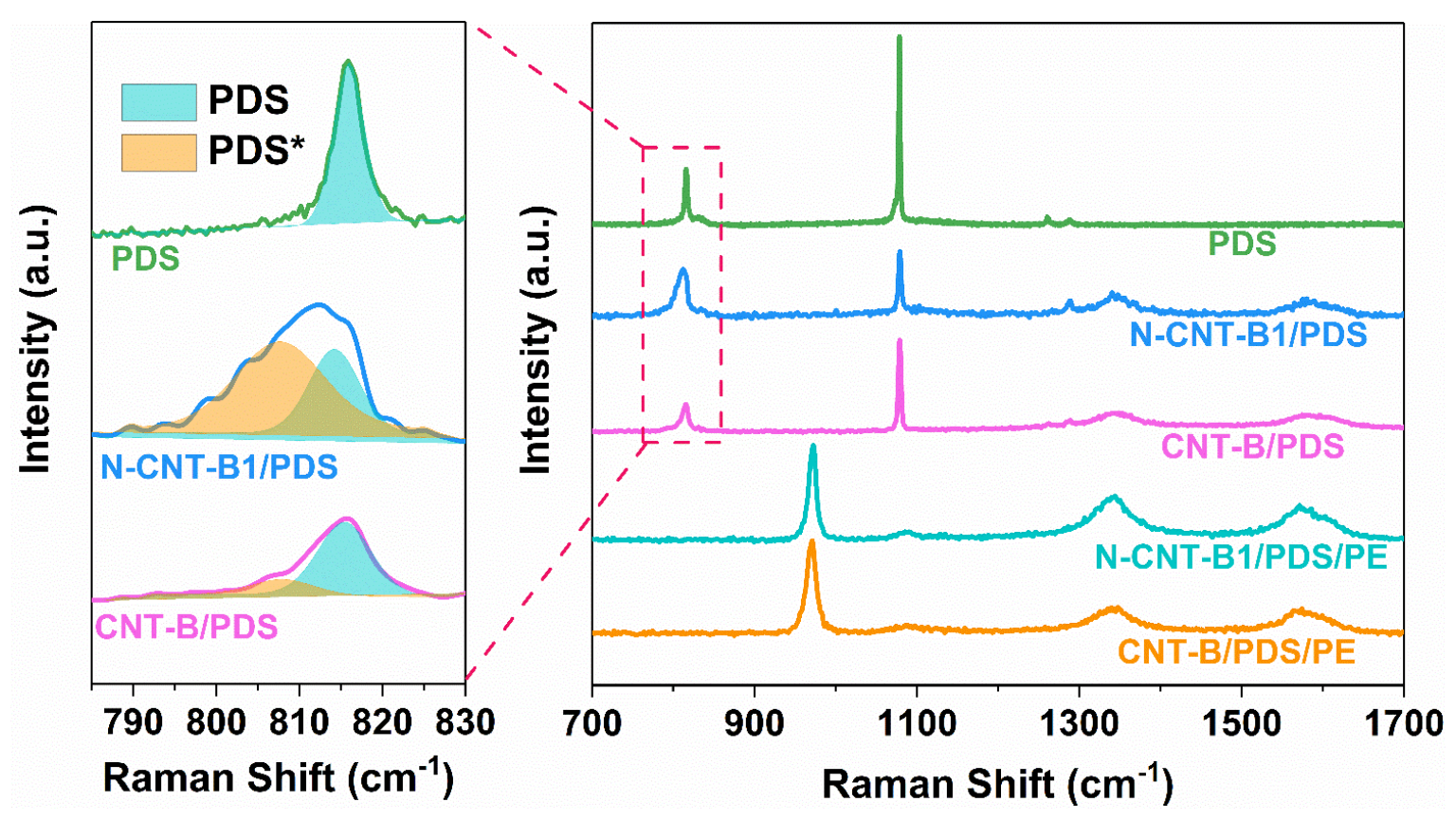

Figure S5. In situ Raman spectra of the PDS/CNT-B and PDS/N-CNT-B1 systems. 

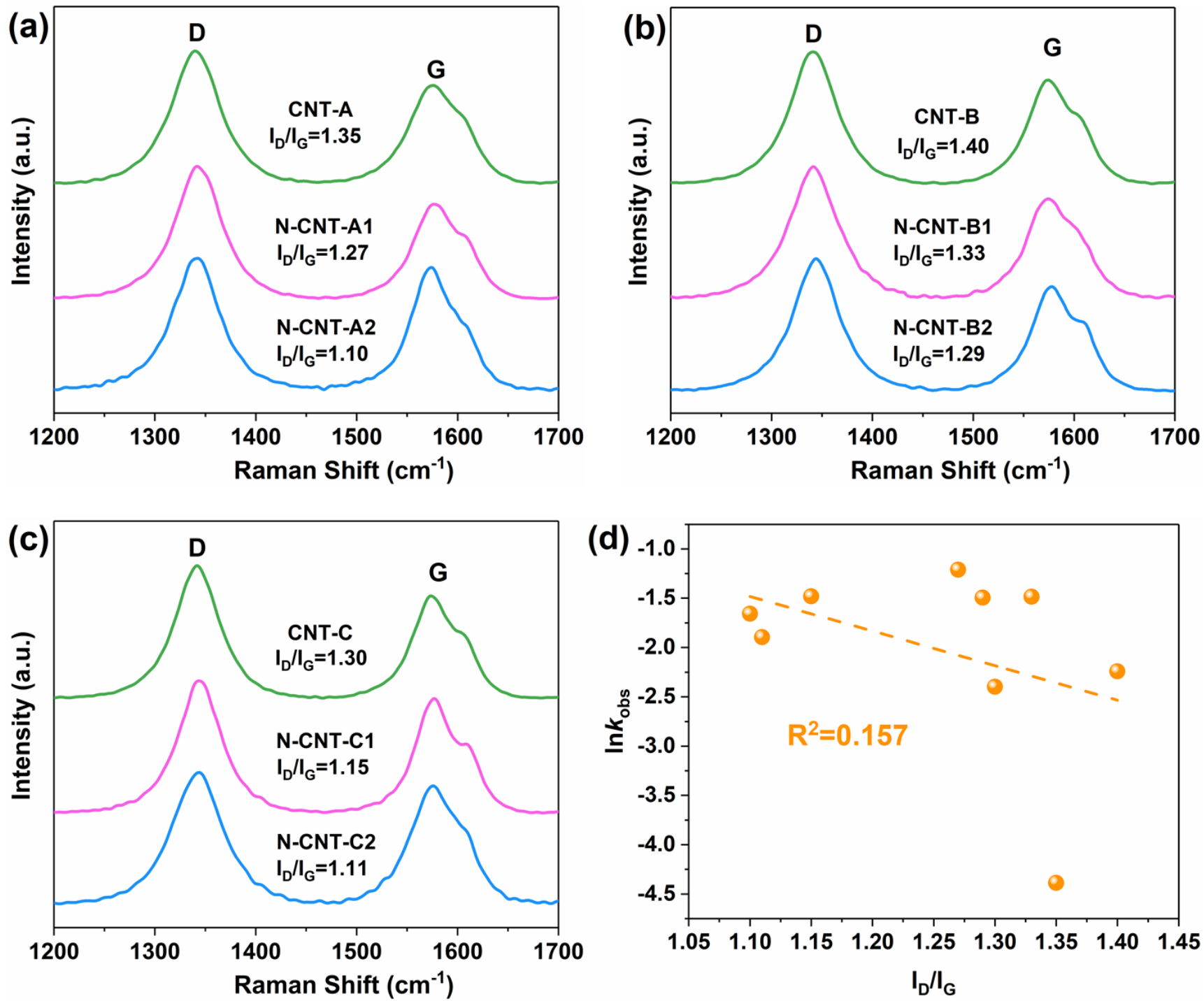

Figure S6. Raman spectra of CNT-A and N-CNT-A materials (a), CNT-B and N-CNT-B materials (b), CNT-C and N-CNT-C materials (c), and the correlation of $\ln k_{\mathrm{obs}}$ to $\mathrm{I}_{\mathrm{D}} / \mathrm{I}_{\mathrm{G}}$ of CNT and N-CNT materials (d). 

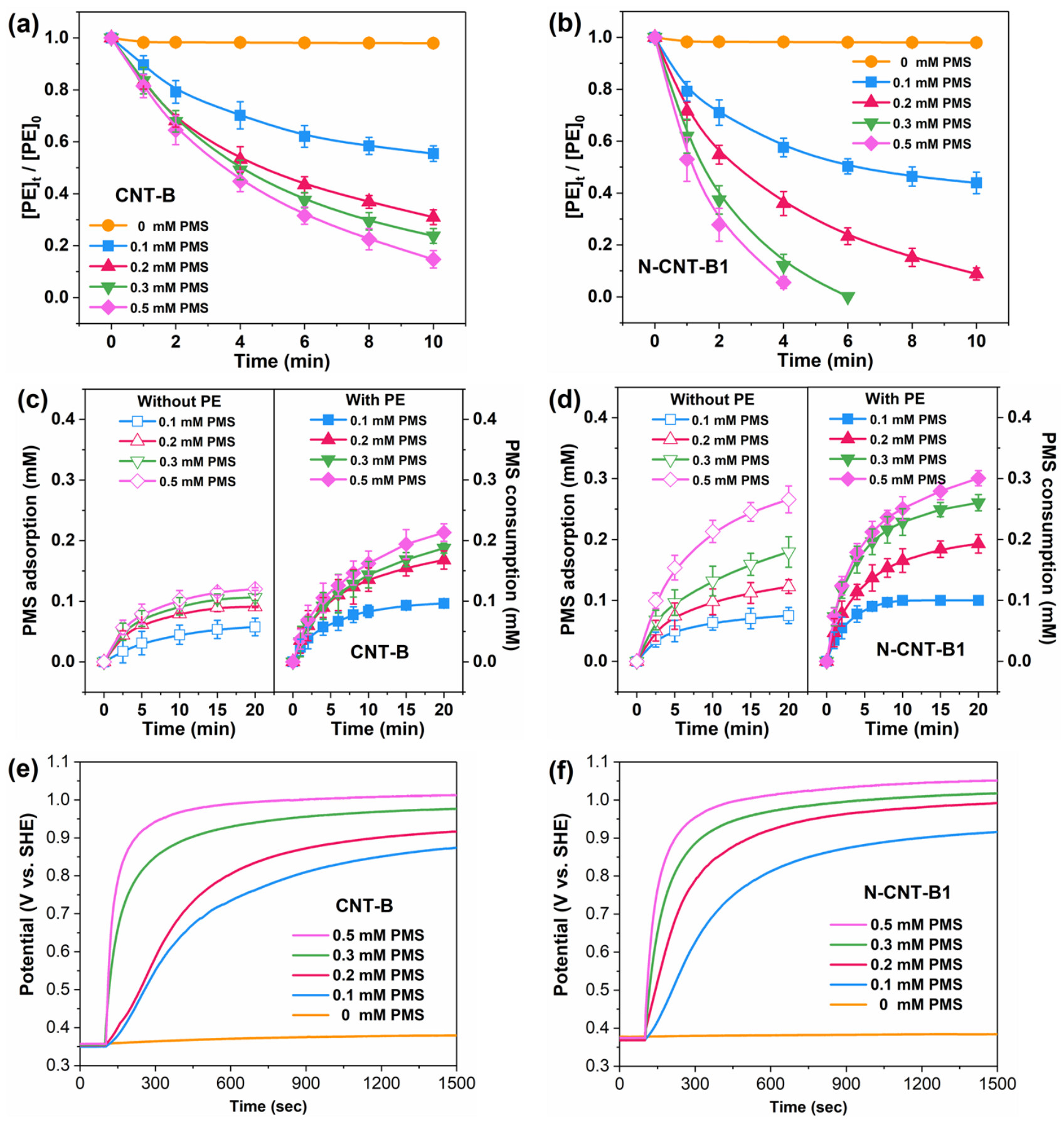

Figure S7. The effects of initial PMS concentration on the degradation of phenol in the PMS/CNT-B (a) and the PMS/N-CNT-B1 (b) systems, on the PMS consumption without or with phenol in the PMS/CNT-B (c) and PMS/N-CNT-B1 (d) systems, and the open-circuit potential of the CNT-B (e) and the N-CNT-B1 (f) electrodes. $\left([\mathrm{CNT}]_{0}=0.1 \mathrm{~g} / \mathrm{L},[\mathrm{PE}]_{0}=0.1 \mathrm{mM}, \mathrm{T}=25^{\circ} \mathrm{C}\right.$ and $\left.\mathrm{pH}_{0} 4.0\right)$ 

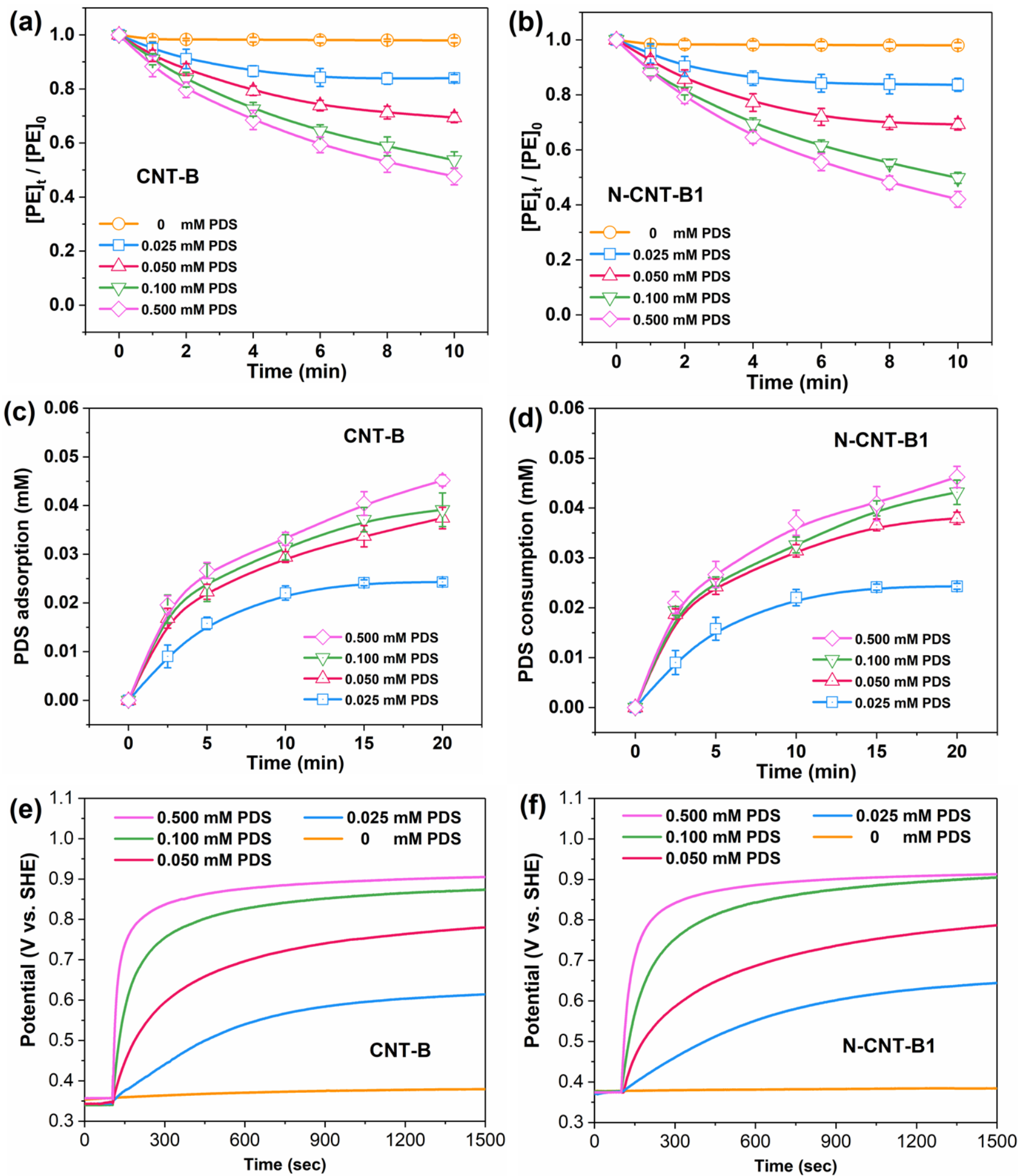

Figure S8. The effects of initial PDS concentration on the degradation of phenol in the PDS/CNT-B (a) and the PDS/N-CNT-B1 (b) systems, on PDS adsorption without phenol in the PDS/CNT-B (c) and the PDS/N-CNT-B1 (d) systems, and on the open-circuit potential of the CNT-B (e) and the N-CNTB1 (f) electrodes. $\left([\mathrm{CNT}]_{0}=0.1 \mathrm{~g} / \mathrm{L},[\mathrm{PE}]_{0}=0.1 \mathrm{mM}, \mathrm{T}=25{ }^{\circ} \mathrm{C}\right.$ and $\left.\mathrm{pH}_{0} 4.0\right)$ 

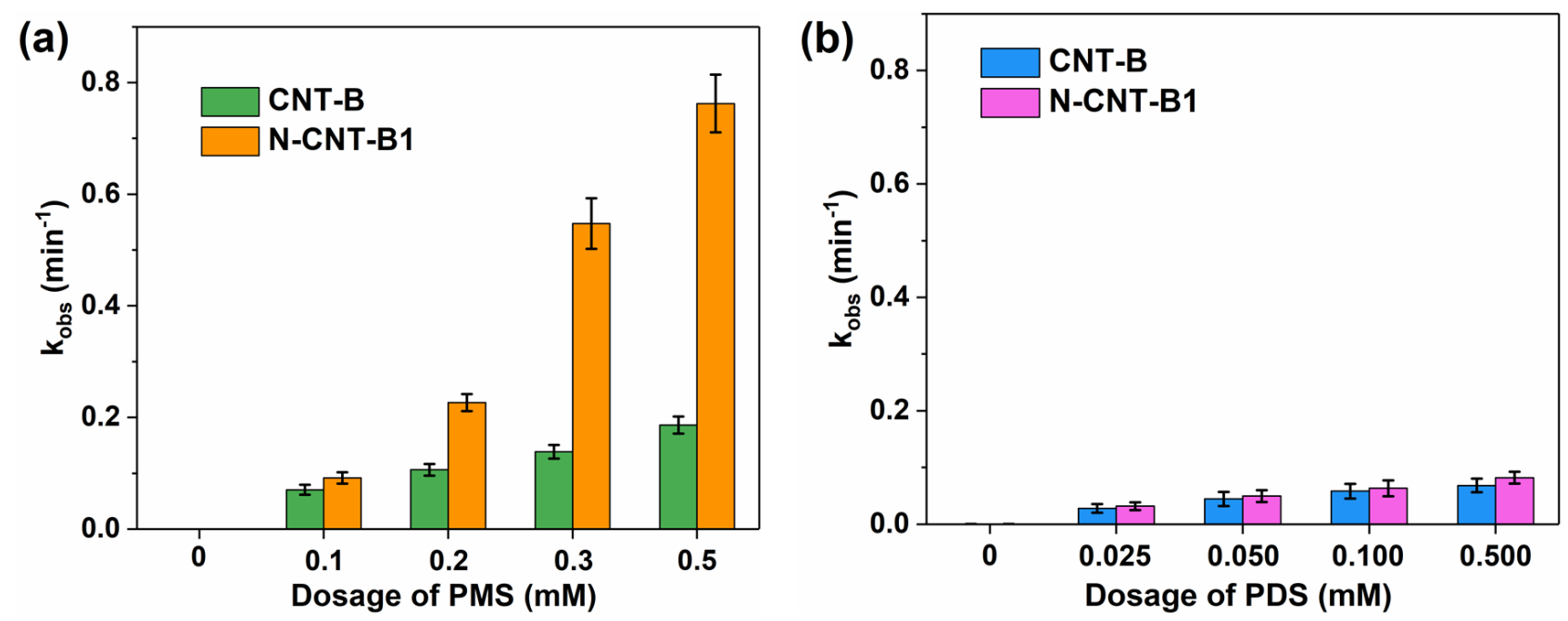

Figure S9. The comparison of $k_{\mathrm{obs}}$ between the persulfate/CNT-B and the persulfate/N-CNT-B1 systems with different initial PMS (a) and PDS (b) concentrations. 


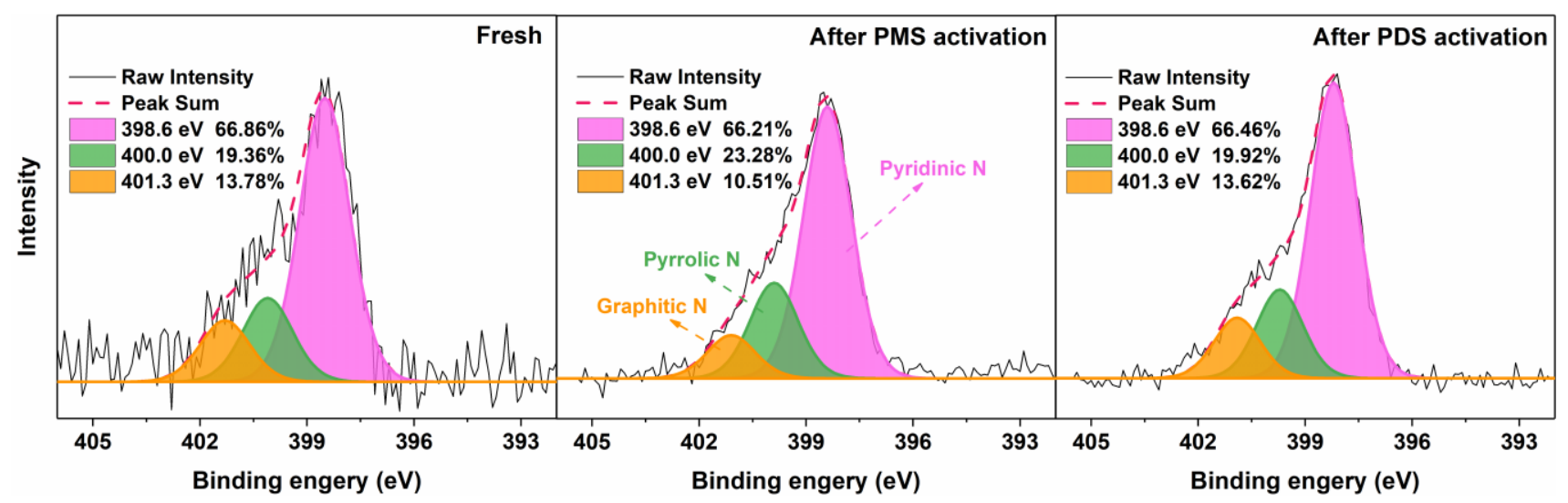

Figure S10. The comparison of N1s XPS spectra of N-CNT-B1 after persulfate activation. 
(a)

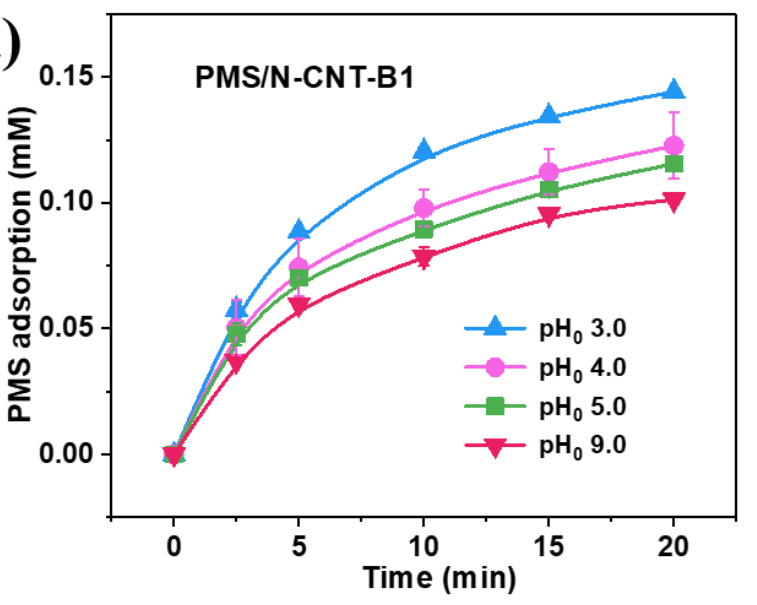

(b)

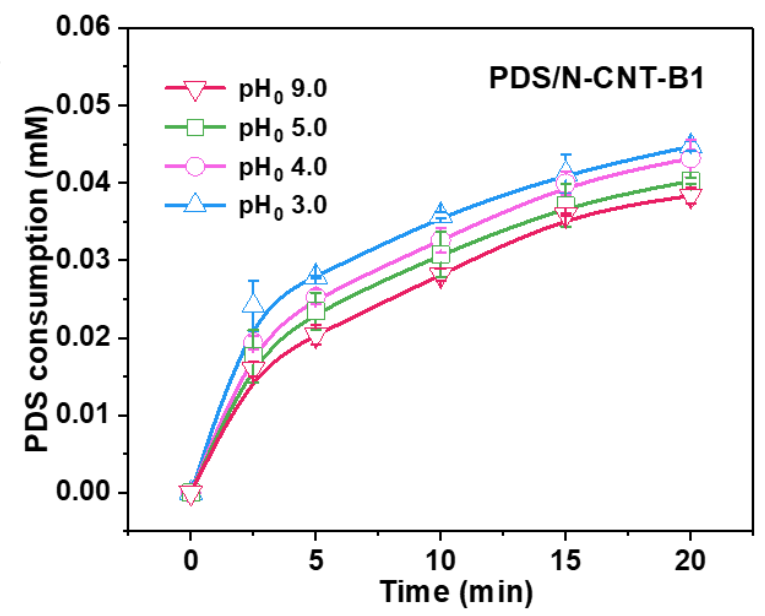

Figure S11. PMS adsorption (a) and PDS adsorption (b) in the persulfate/N-CNT-B1 systems at different initial pHs. $\left([\text { persulfate }]_{0}=0.2 \mathrm{mM},[\mathrm{N}-\mathrm{CNT}-\mathrm{B} 1]_{0}=0.1 \mathrm{~g} / \mathrm{L}\right.$ and $\left.\mathrm{T}=25^{\circ} \mathrm{C}\right)$ 

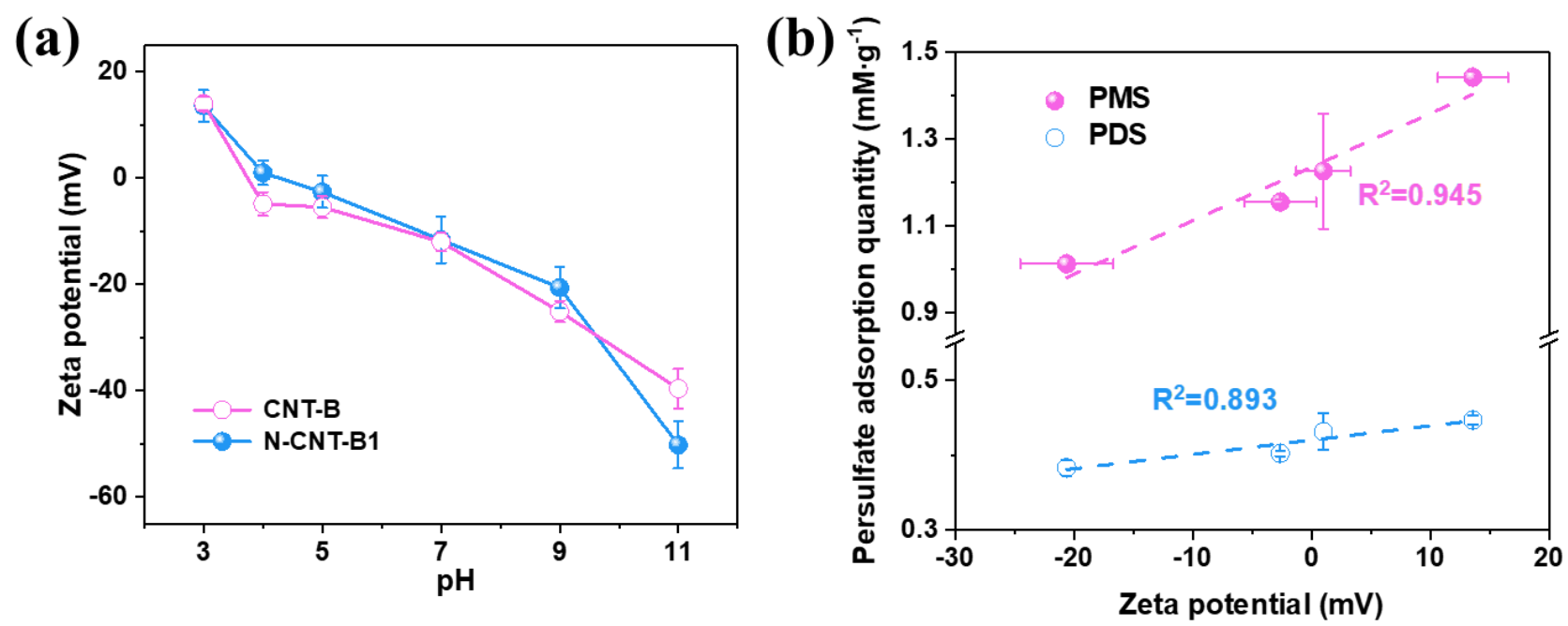

Figure S12. Zeta potentials of CNT-B and N-CNT-B1 in different pHs (a); and correlation of persulfate adsorption quantity with the Zeta potential of N-CNT-B1 (b). 

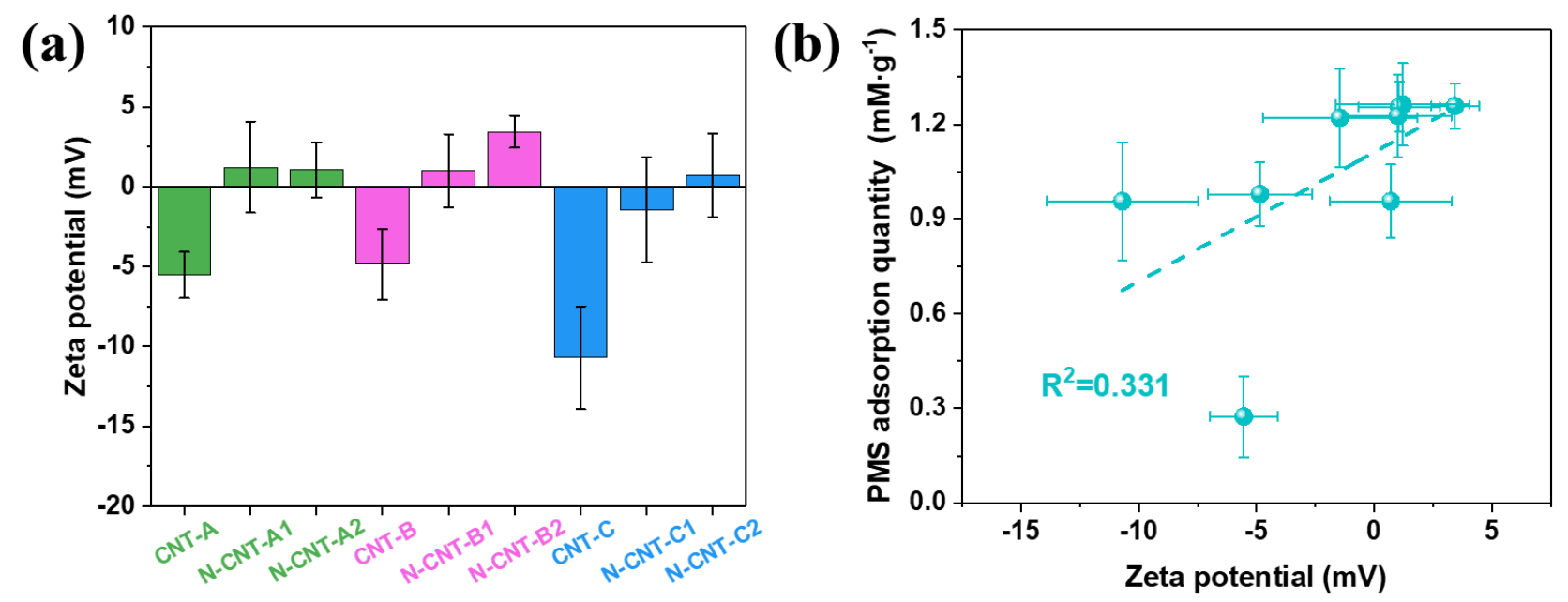

Figure S13. Zeta potentials of different CNT materials (a) and correlation of PMS adsorption quantity with the Zeta potential (b). ( $\mathrm{T}=25^{\circ} \mathrm{C}$ and $\left.\mathrm{pH}_{0} 4.0\right)$ 
(a)

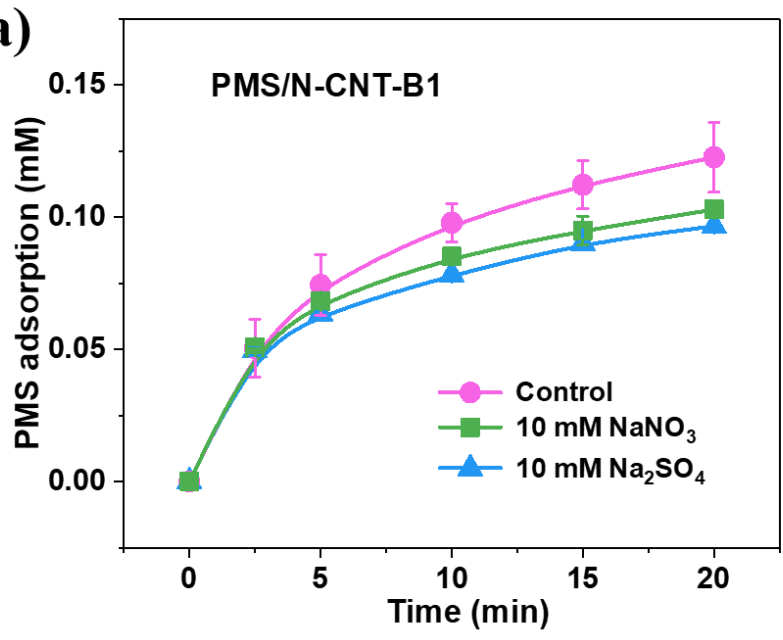

(b)

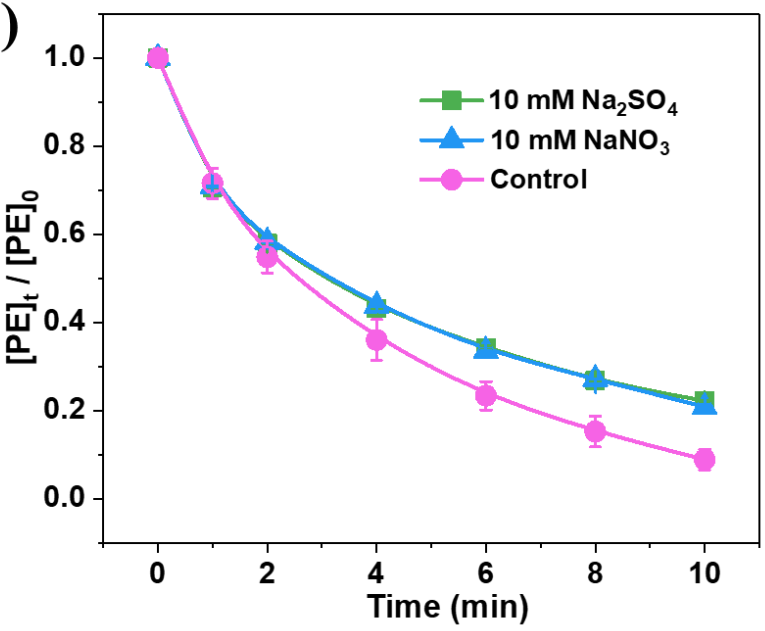

Figure S14. The effect of inorganic ions on PMS adsorption (a) and PE degradation (b) in the PMS/NCNT-B1 system. $\left([\mathrm{PMS}]_{0}=0.2 \mathrm{mM},[\mathrm{N}-\mathrm{CNT}-\mathrm{B} 1]_{0}=0.1 \mathrm{~g} / \mathrm{L},[\mathrm{PE}]_{0}=0 \text { or } 0.1 \mathrm{mM} \text {, [inorganic ions }\right]_{0}$ $=10 \mathrm{mM}, \mathrm{T}=25^{\circ} \mathrm{C}$ and $\left.\mathrm{pH}_{0} 4.0\right)$ 

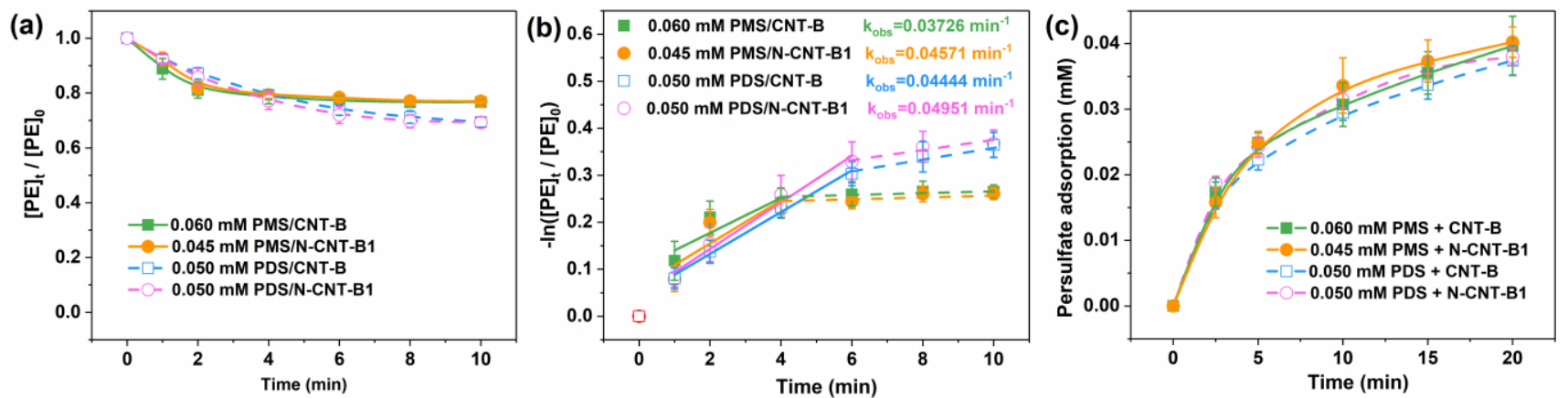

Figure S15. The degradation curves of phenol with equal adsorption quantity of persulfate on the CNT-

B and N-CNT-B1 materials (a), the corresponding pseudo-first-order kinetics (b), and the change of persulfate adsorption (c) by persulfate/CNT and persulfate/N-CNT systems. $\left([\mathrm{CNT}]_{0}=0.1 \mathrm{~g} / \mathrm{L},[\mathrm{PE}]_{0}\right.$ $=0.1 \mathrm{mM}, \mathrm{T}=25^{\circ} \mathrm{C}$ and $\left.\mathrm{pH}_{0} 4.0\right)$ 

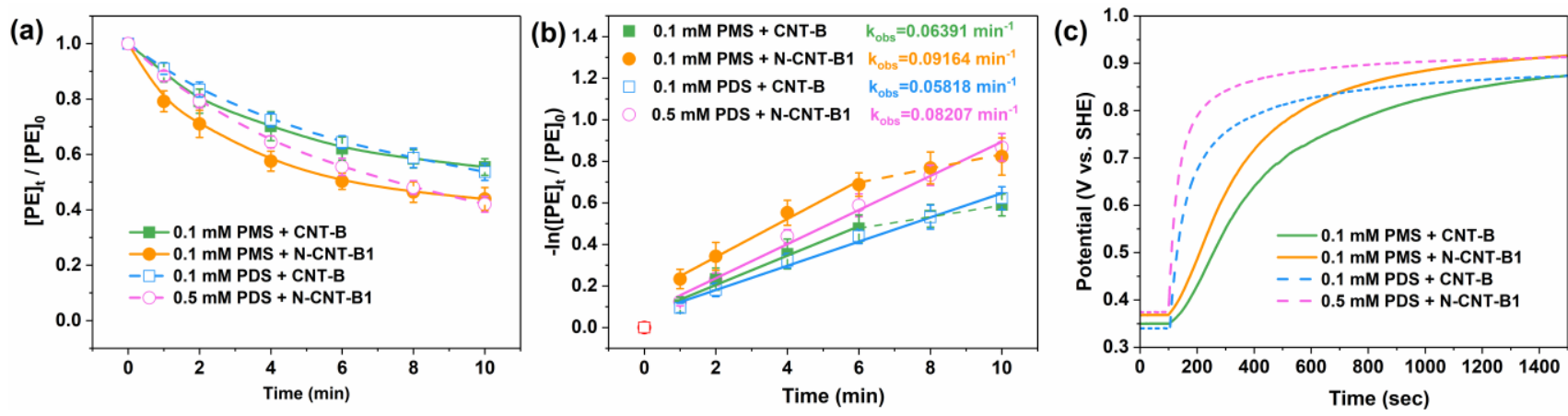

Figure S16. The degradation curves of phenol with equal potential of complexes on the CNT-B and N-CNT-B1 materials (a), the corresponding pseudo-first-order kinetics (b), and the change of persulfate adsorption (c) by persulfate/CNT and persulfate/N-CNT systems. ([CNT $]_{0}=0.1 \mathrm{~g} / \mathrm{L},[\mathrm{PE}]_{0}$ $=0.1 \mathrm{mM}, \mathrm{T}=25^{\circ} \mathrm{C}$ and $\left.\mathrm{pH}_{0} 4.0\right)$ 


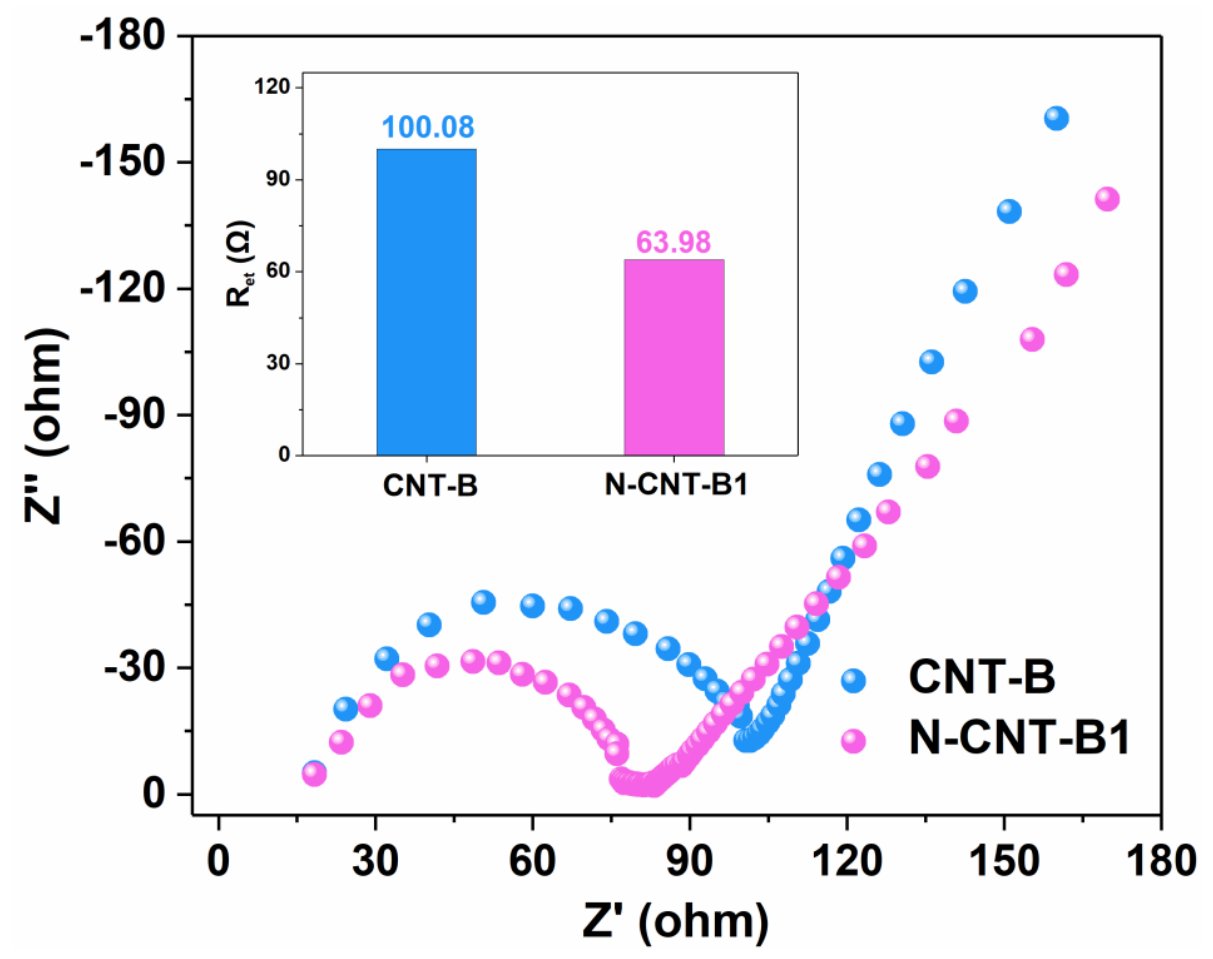

Figure S17. The electrochemical impedance spectroscopy profiles of the CNT-B and N-CNT-B1 electrodes in the electrolyte solution. $\left(\left[\mathrm{Na}_{2} \mathrm{SO}_{4}\right]_{0}=50 \mathrm{mM}, \mathrm{T}=25^{\circ} \mathrm{C}\right.$ and $\left.\mathrm{pH}_{0} 4.0\right)$ 


\section{Reference}

S1. Liang, C.; Huang, C. F.; Mohanty, N.; Kurakalva, R. M., A rapid spectrophotometric determination of persulfate anion in ISCO. Chemosphere 2008, 73, 1540-1543. 